\title{
SEVERE BRADYCARDIA AND ASYSTOLIA ASSOCIATED WITH SUGAMMADEX
}

Catarina Oliveira, Vânia Simões, Catarina Marques, Leina Spencer, Rita Poeira, Margarida Casteleira Centro Hospitalar Lisboa Central; Anesthesiology Department - Dra. Isabel Fragata

\section{INTRODUCTION}

Sugammadex is a selective relaxant binding agent, recently introduced to reverse neuromuscular blockade induced by rocuronium and vecuronium. Its efficacy and safety are well demonstrated in multiple clinical trials, being severe cardiac adverse events a rarity $(<1 \%)^{1}$.

\section{CASE Report}

\section{Incarcerated umbilical hernia - Urgent herniorraphy}

- Male, 54 yrs old, past history of hypertension, dyslipidemia and obesity

- Rapid sequence induction: Fentanyl $(2 \mu \mathrm{g} / \mathrm{kg})$, Propofol $(2 \mathrm{mg} / \mathrm{kg})$, Succinylcholine $(1,5 \mathrm{mg} / \mathrm{kg})$

- Maintenance of anaesthesia: Desflurane

- Neuromuscular blockade: Rocuronium

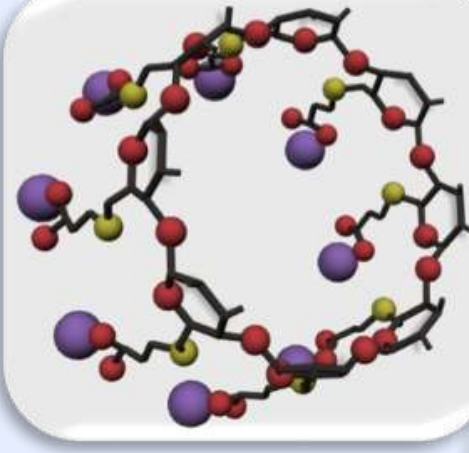

- Surgery lasted $20 \mathrm{~min}$ and proceeded uneventfully

\section{End of surgery}

TOF 2

Sugammadex

200mg IV

\section{$30 \mathrm{sec}$ later}

Marked bradycardia (30bpm) followed by asystolia Atropine $1 \mathrm{mg}$ IV Chest compressions

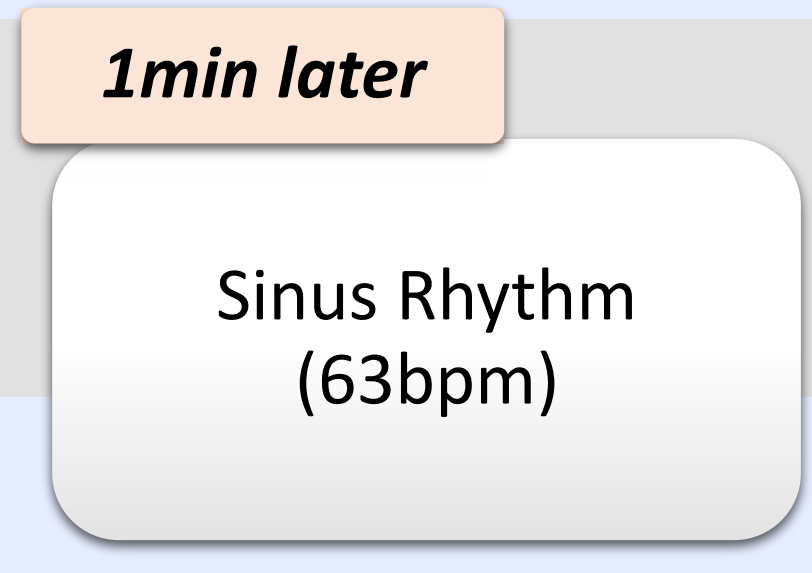

\section{2 min later}

Spontaneous ventilation Extubation

PACU and hospital stay: patient remained stable Clinical discharged: $48 \mathrm{~h}$ later

\section{DISCUSSION}

Marked bradycardia and cardiac arrest may be observed after the administration of sugammadex ${ }^{1}$. As far as we know, there's just one case reporting severe bradycardia induced by sugammadex ${ }^{2}$. Disturbance in cardiac conductance can occur but no cases of arrhythmia have been reported. Cases of cardiovascular collapse have been described in the context of hypersensitivity reactions and never as a cardiac side effect ${ }^{3}$.

Our case is a reminder that cardiac arrest is a rare but possible side effect of sugammadex and that awareness must be raised for a successful outcome. 